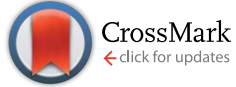

Cite this: RSC Adv., 2015, 5, 35909

Received 30th March 2015 Accepted 10th April 2015

DOI: $10.1039 / \mathrm{c} 5 \mathrm{ra05625j}$

www.rsc.org/advances

\section{Polyvinylidene fluoride based lightweight and corrosion resistant electromagnetic shielding materials}

\author{
Viraj Bhingardive, $\uparrow^{\mathrm{a}}$ Maya Sharma, $\uparrow^{\mathrm{b}}$ Satyam Suwas, ${ }^{\mathrm{a}}$ Giridhar Madras ${ }^{\mathrm{c}}$ \\ and Suryasarathi Bose*a
}

\begin{abstract}
Various $\mathrm{Ni}_{x} \mathrm{CO}_{1-x}$ alloys (with $x$ varying from $0-60 \mathrm{wt} \%$, Ni: nickel, Co: cobalt) were prepared by vacuum arc melting and mixed with polyvinylidene fluoride (PVDF) to design lightweight, flexible and corrosion resistant materials that can attenuate electromagnetic radiation. The saturation magnetization scaled with the fraction of $\mathrm{Co}$ in the alloy. Two key properties such as high-magnetic permeability and high-electrical conductivity were targeted. While the former was achieved using a $\mathrm{Ni}-\mathrm{Co}$ alloy, multiwalled carbon nanotubes (CNTs) in the composites accomplished the latter. A unique approach was adopted to prepare the composites wherein PVDF powder along with CNTs and Ni-Co flakes were made into a paste, using a solvent, followed by hot pressing. Interestingly, CNTs facilitated in uniform dispersion of the $\mathrm{Ni}-\mathrm{Co}$ alloy in PVDF, as manifested from synergistic improvement in the electrical conductivity. A significant improvement in the shielding effectiveness (41 dB, >99.99\% attenuation) was achieved with the addition of $50 \mathrm{wt} \%$ of $\mathrm{Ni}_{40} \mathrm{CO}_{60}$ alloy and $3 \mathrm{wt} \%$ CNTs. Intriguingly, due to the unique processing technique adopted here, the flexibility of the composites was retained and more interestingly, the composites were resistant to corrosion as compared to only $\mathrm{Ni}-\mathrm{Co}$ alloy.
\end{abstract}

\section{Introduction}

Electromagnetic (EM) interference has become a major concern because of increasing demand for electronic equipment and various devices operating at high frequencies. ${ }^{1-5}$ Devices like wireless computers, mobile phones, microwaves and radios emit EM radiation., ${ }^{3,46}$ This EM radiation can cause severe damage to the system itself and/or other electronic devices in the vicinity ultimately leading to malfunctioning of devices. ${ }^{1}$ Further, advancement in nanotechnology has resulted in densely packed ${ }^{2}$ electronic components within an instrument causing electronic noise and creating a problem of interference with other systems by radiation. These emissions, in addition, have adverse effects on the human body and causes serious damage to human tissues. ${ }^{\mathbf{1}, 2,6} \mathrm{EM}$ frequencies ranging from low to high causes flow of current through human body and generate heat and thermal injury to the human system. ${ }^{\mathbf{1 , 2 , 6}}$ High frequency sources such as mobile phones, $\mathrm{WLAN}^{1}$ etc. affects

\footnotetext{
${ }^{a}$ Department of Materials Engineering, Indian Institute of Science, Bangalore-560012, India. E-mail: sbose@materials.iisc.ernet.in; Fax: +91-80-23600472; Tel: +91-8022933407

${ }^{b}$ Centre for Nanoscience and Engineering, Indian Institute of Science, Bangalore560012, India

${ }^{c}$ Department of Chemical Engineering, Indian Institute of Science, Bangalore-560012, India

$\dagger \mathrm{VB}$ and MS contributed equally to this work.
}

the nervous system. ${ }^{2}$ Therefore, devices that are vulnerable to EM radiation need to be shielded to avoid their malfunctioning. It is, therefore, important to understand the properties and behavior of EM radiations in order to shield them.

EM radiations are due to synchronized oscillations of electric and magnetic fields at right angles to each other and to the direction of propagation., ${ }^{5,7}$ These radiations can be arrested or reduced by either absorption and/or reflection. Conducting polymer matrix composites have received significant attention in effective shielding of EM radiations due to their high conductivity and dielectric constant. ${ }^{5,9}$ The absorption loss in the shielding material is a function of magnetic permeability and the conductivity of the material. ${ }^{5}$ Therefore, incorporating magnetic particles within conducting polymer composites can promise materials that can attenuate the radiations. Therefore, these materials will possess a unique combination of both magnetic and electrical dipoles in the system. Conducting fillers such as carbon black, metallic particles, carbon nanotubes (CNTs), graphene etc. are the most widely used materials for improving the conductivity of a polymer matrix., ${ }^{5,7,8,10}$ The ability of metals to conduct heat and electricity is the reason for their widespread use in EMI shielding. However, the disadvantages with metals are their bulkiness, poor processability, and poor oxidation resistance. In addition, metallic coating is costly since it consists of at least two processing steps, such as one for the support and other for the coating. Moreover, it is very difficult to coat intricate shapes. ${ }^{7}$ In this context, low- 
density carbon nanostructures are effective material for EM interference shielding as it has high current density. In addition, they have high aspect ratio, which facilitates interconnected network like structure at relatively lower fractions. Overall, these properties makes CNT based polymeric composites a promising candidate $\mathbf{8}^{\mathbf{8 1 1}}$ over conventional materials.

In the recent past, ferromagnetic particles like $\mathrm{Fe} \mathrm{Co}, \mathrm{Ni}$ and their alloy have received a great deal of attention due to their potential use as electromagnetic shielding materials in the gigahertz frequency region. In addition, owing to their high Snoek's limit ${ }^{12}$ they are ideal candidates among the metallic and alloy magnet class of materials. ${ }^{13}$ Further, carbon/ferromagnetic composites exhibit a good balance between permittivity and permeability. ${ }^{14-18}$

In the light of the existing literature, we aim to develop lightweight, flexible, and corrosion resistant polymeric composites containing small volume fractions of ferromagnetic material with high magnetic permeability and intrinsically conducting nanomaterials like CNTs. Therefore, nickel-cobalt alloys with different compositions were prepared by vacuum arc melting process and mixed with CNTs using a unique processing technique for shielding EM radiations. Polyvinylidene fluoride (PVDF) was chosen as a matrix because of its high dielectric constant, good mechanical properties, thermal stability and chemical resistance. ${ }^{11}$ Arranz-Andrés et al. reported that a shielding effectiveness (SE) of $110 \mathrm{~dB}$ on addition of 25 vol\% of copper in the PVDF matrix. ${ }^{3}$ Chung et al. achieved shielding effectiveness of $90 \mathrm{~dB}$ in the range of $1-2 \mathrm{GHz}$ by coating carbon filaments with nickel (94 vol\%) in polyether sulfone. ${ }^{19,20}$ Gong et al. reported ca. $25 \mathrm{~dB}$ with $50 \mathrm{wt} \% \mathrm{Ni}$ in resin based matrix. ${ }^{21}$ Recently, we have reported SE of $30 \mathrm{~dB}$ with 3 wt\% CNTs in PVDF matrix. The results obtained in our previous work further motivated us to systematically study the effect of Ni-Co alloy on the shielding effectiveness in PVDF based composites. Flakes of Ni-Co alloy was chosen over fine powder as they possess high permeability than the spherical particle $^{12}$ especially, in the GHz range. ${ }^{\mathbf{1 4 2 2 - 2 4}}$ The properties of CNTs and Ni-Co alloy will provide synergistic improvement in the key properties like electrical conductivity, magnetic permeability and dielectric properties that are required to design an efficient shield against EM radiation. The structure, morphology and the EMI shielding properties of the composites has been discuss in detail and summarized.

\section{Experimental}

\subsection{Materials and methods}

$\mathrm{Ni}_{x} \mathrm{Co}_{1-x}$ alloys $(x=0-60 \mathrm{wt} \%)$ were prepared by vacuum arc melting technique from high purity elemental constituents. The as-cast alloys were subjected to hot rolling followed by homogenization anneal and then air-cooled. The microstructural details of Ni-Co alloys have been already reported in our previous study. ${ }^{25,26} \mathrm{Ni}-\mathrm{Co}$ alloy powder (flaky shaped) was obtained by filing with a diamond file. Commercially available PVDF (Kynar 741), supplied by Arkema, was used in this work. The pristine CNTs were obtain from Nanocyl (NC 7000). Both PVDF and the flakes were mixed using a mortar pestle for
30 min and the solvent (dimethylformamide, DMF) was added drop-wise to make a paste. This unique approach was adopt because the metal powder tends to agglomerate during processing either in solution or in melt. The resultant paste was then vacuum dried to remove the traces of solvent followed by compression moulding at $220^{\circ} \mathrm{C}$ in a laboratory scale hot press. PVDF with 50 wt $\% \mathrm{Ni}_{40} \mathrm{Co}_{60}$ alloy and PVDF + $3 \mathrm{wt} \%$ CNTs + $50 \mathrm{wt} \% \mathrm{Ni}_{40} \mathrm{Co}_{60}$ alloy was prepared employing the above mentioned procedure.

\subsection{Characterization}

The magnetic response of various $\mathrm{Ni}-\mathrm{Co}$ flakes and the composites were obtain using vibrating sample magnetometer (VSM). The morphology and the state of dispersion of the flakes and CNTs in PVDF were investigated by employing a field emission scanning electron microscope (FEI Sirion XL30 FEG SEM). The composite samples were cryo-fractured prior to SEM. The X-ray diffraction patterns were studied using a PANalytical X'pert Pro $(\mathrm{Cu} \mathrm{K} \alpha, \lambda=0.154 \mathrm{~nm})$. Toroidal samples were prepared for evaluating the scattering parameters in the frequency range of 2-18 GHz using Anritsu MS4642A Vector Network Analyzer (VNA). Electrical conductivity of hot pressed discs $(10 \mathrm{~mm})$ was measured by employing an Alpha-N analyser (Novocontrol) with a broad frequency range of $10^{-1}$ to $10^{7} \mathrm{~Hz}$. The corrosion resistance of the composite sample was compared with Ni-Co alloy by Potentio-dynamic polarization in $0.5 \% \mathrm{NaCl}$ media. The test was conducted by employing a platinum strip, saturated calomel electrode and Ni-Co alloy (or composite sample) as a counter electrode, reference electrode and working electrode respectively. The corrosion current density $\left(I_{\text {corr }}\right)$ and potential $\left(E_{\text {corr }}\right)$ were determined with the Tafel plot. The scan rate for polarization was $12 \mathrm{mV} \mathrm{min}^{-1}$ from $-150 \mathrm{mV}$ to $+1500 \mathrm{mV}$ relative to the rest potential.

\section{Results and discussion}

\subsection{Preparation and characterization of Ni-Co alloy}

Fig. 1a illustrates schematically the preparation of Ni-Co alloy using vacuum arc melting process. The microstructure of the hot rolled and homogenization annealed alloy is illustrated in Fig. 1b. The ingot, thus obtained was filed to obtain into powder of specific size. The morphology of the powder, as revealed by SEM, is flaky (Fig. 1c) with size of ca. 3-4 $\mu \mathrm{m}$. Fig. 1d shows the XRD pattern for Ni-Co flakes. Three peaks at $44.48^{\circ}, 51.66^{\circ}$ and $76.06^{\circ}$, corresponding to (111), (200) and (220) plane of Ni-Co alloy are observed indicating that the as prepared $\mathrm{Ni}-\mathrm{Co}$ alloy is a solid solution with face-centred cubic (FCC). The XRD pattern also indicates absence of impurity or second phase in the Ni-Co alloy. Fig. 1e shows the typical hysteresis loop for pure nickel and $\mathrm{Ni}-\mathrm{Co}$ alloy $(20,40,60 \mathrm{wt} \% \mathrm{Co})$ flakes obtained at room temperature using a magnetic field of $2 \mathrm{~T}$. The saturation magnetization scales with cobalt concentration in the alloy. The values of saturation magnetization for pure $\mathrm{Ni}, \mathrm{Ni}_{80} \mathrm{Co}_{20}, \mathrm{Ni}_{60} \mathrm{Co}_{40}$ and $\mathrm{Ni}_{40} \mathrm{Co}_{60}$ are $50.2,74.1,101.2$ and $117.3 \mathrm{emu} \mathrm{g}^{-1}$, respectively. Thus, $\mathrm{Ni}_{40} \mathrm{Co}_{60}$ shows the highest magnetic permeability compared to pure nickel and other composition. Therefore, it is desirable to design 
(a)
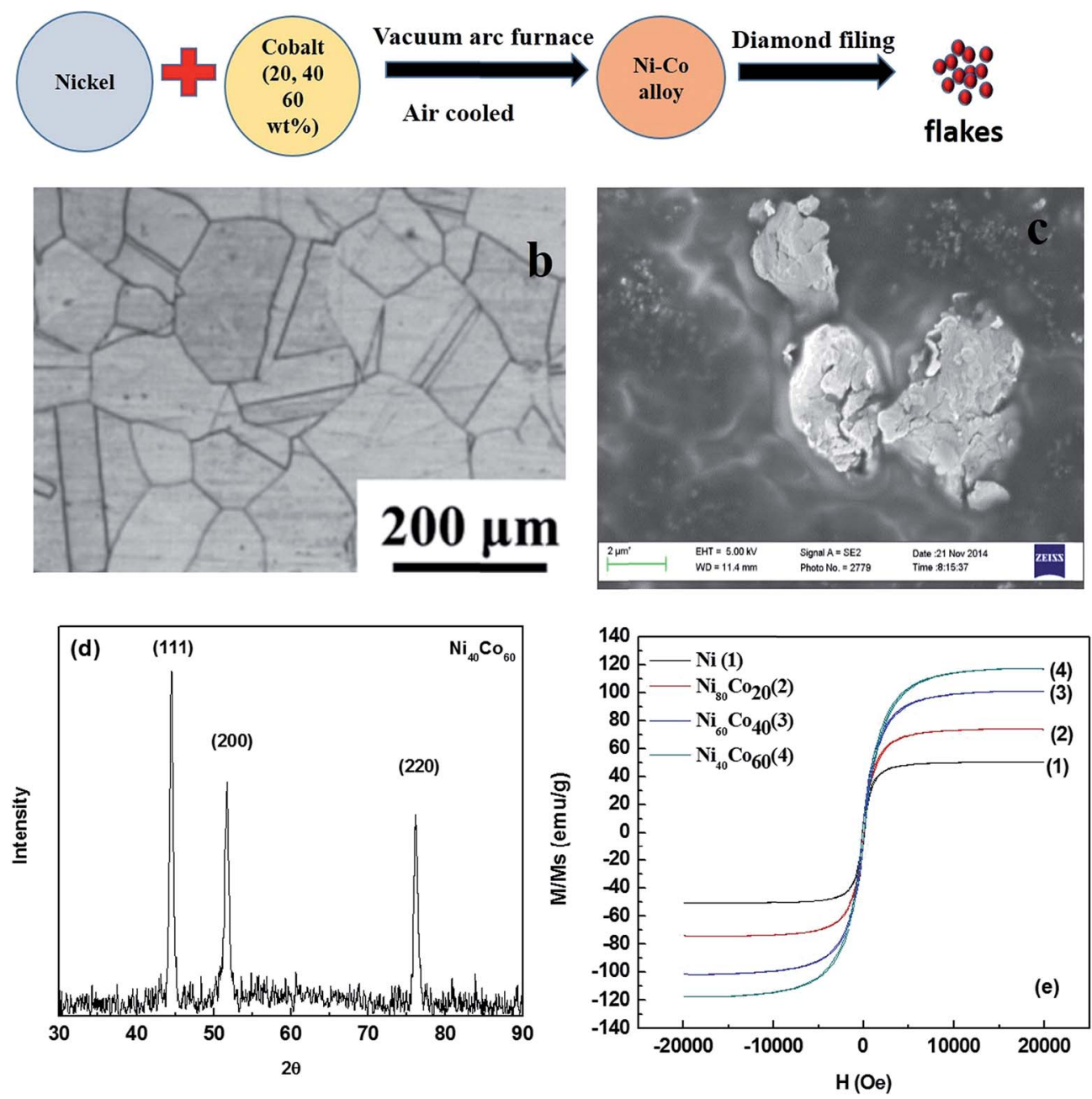

Fig. 1 (a) Processing of Ni-Co alloy (b) SEM image of Ni-Co alloy flakes (c) microstructure of the hot rolled plus homogenization annealed alloy, (d) XRD pattern for $\mathrm{Ni}-\mathrm{Co}$ alloy powder (e) hysteresis loop for $\mathrm{Ni}-\mathrm{Co}$ alloy with varying concentration of cobalt.

composites using $\mathrm{Ni}_{40} \mathrm{Co}_{60}$ to obtain materials that can attenuate EM radiation mostly by absorption.

\subsection{Preparation and characterization of PVDF based composites}

Fig. 2a schematically illustrates the preparation of PVDF/CNT/ $\mathrm{Ni}_{40} \mathrm{Co}_{60}$ composite. The slurry is prepared by physically mixing the constituents by drop-wise addition of solvent. Subsequently the composite is hot pressed after vacuum dried as shown in Fig. 2a. This unique process was adopted for two main reasons. Firstly, metal flakes usually settle during the composite preparation by solution mixing process. Secondly, they tend to reagglomerate during melt blending. By employing this process, we believe, that the metal flakes together with CNT can be dispersed well in PVDF. The XRD patterns of as prepared $\mathrm{PVDF} / \mathrm{CNT} / \mathrm{Ni}_{40} \mathrm{Co}_{60}$ composite and $\mathrm{PVDF} / \mathrm{Ni}_{40} \mathrm{Co}_{60}$ composite are shown in Fig. 2b. In addition to the three FCC peaks corresponding to $\mathrm{Ni}-\mathrm{Co}$ alloy in the $\mathrm{XRD}$ pattern, it shows three additional peaks at $18.46^{\circ}, 20.09^{\circ}$ and $26.76^{\circ}$ which corresponds to (020), (110) and (021) of PVDF. Fig. 2c shows the comparative hysteresis loop for $\mathrm{PVDF} / \mathrm{CNT} / \mathrm{Ni}_{40} \mathrm{Co}_{60}$ and $\mathrm{PVDF} / \mathrm{Ni}_{40} \mathrm{Co}_{60}$ composites. From Fig. 2c, it is clear that the saturation magnetization decreased after the addition of PVDF. The saturation magnetization of PVDF with $\mathrm{Ni}_{40} \mathrm{Co}_{60}(20 \%$ by wt) is 19.2 emu $\mathrm{g}^{-1}$ compared to PVDF/CNTs (3\% by wt)/ $\mathrm{Ni}_{40} \mathrm{Co}_{60}\left(50 \%\right.$ by wt) composite which showed $50.63 \mathrm{emu} \mathrm{g}^{-1}$. It is well evident that the magnetic permeability of PVDF/CNT/ $\mathrm{Ni}_{40} \mathrm{Co}_{60}$ is higher than that of PVDF/ $\mathrm{NiCo}_{60}(20 \% \mathrm{wt})$ respectively are $2.5 \times 10^{-3}$ and $9.8 \times 10^{-4} \mathrm{H} \mathrm{m}^{-1}$. The magnetic permeability of PVDF/CNTs-NiCo 60 is almost similar to pure nickel (Fig. 1d and 2(c)).

The SEM images of neat PVDF, PVDF/ $\mathrm{Ni}_{40} \mathrm{Co}_{60}, \mathrm{PVDF} / \mathrm{CNTS}$ and $\mathrm{PVDF} / \mathrm{CNT} / \mathrm{Ni}_{40} \mathrm{Co}_{60}$ composites are shown in Fig. $3 \mathrm{a}-\mathrm{d}$. It is observed that both CNTs and Ni-Co alloy flakes are relatively well dispersed in PVDF. Interestingly, Fig. $3 \mathrm{~d}$ shows that the CNTs are well connected in presence of $\mathrm{Ni}_{40} \mathrm{Co}_{60}$ flakes. Such phenomenal dispersion can result in significant enhancement in the bulk electrical conductivity and will be discussed in the subsequent section. 

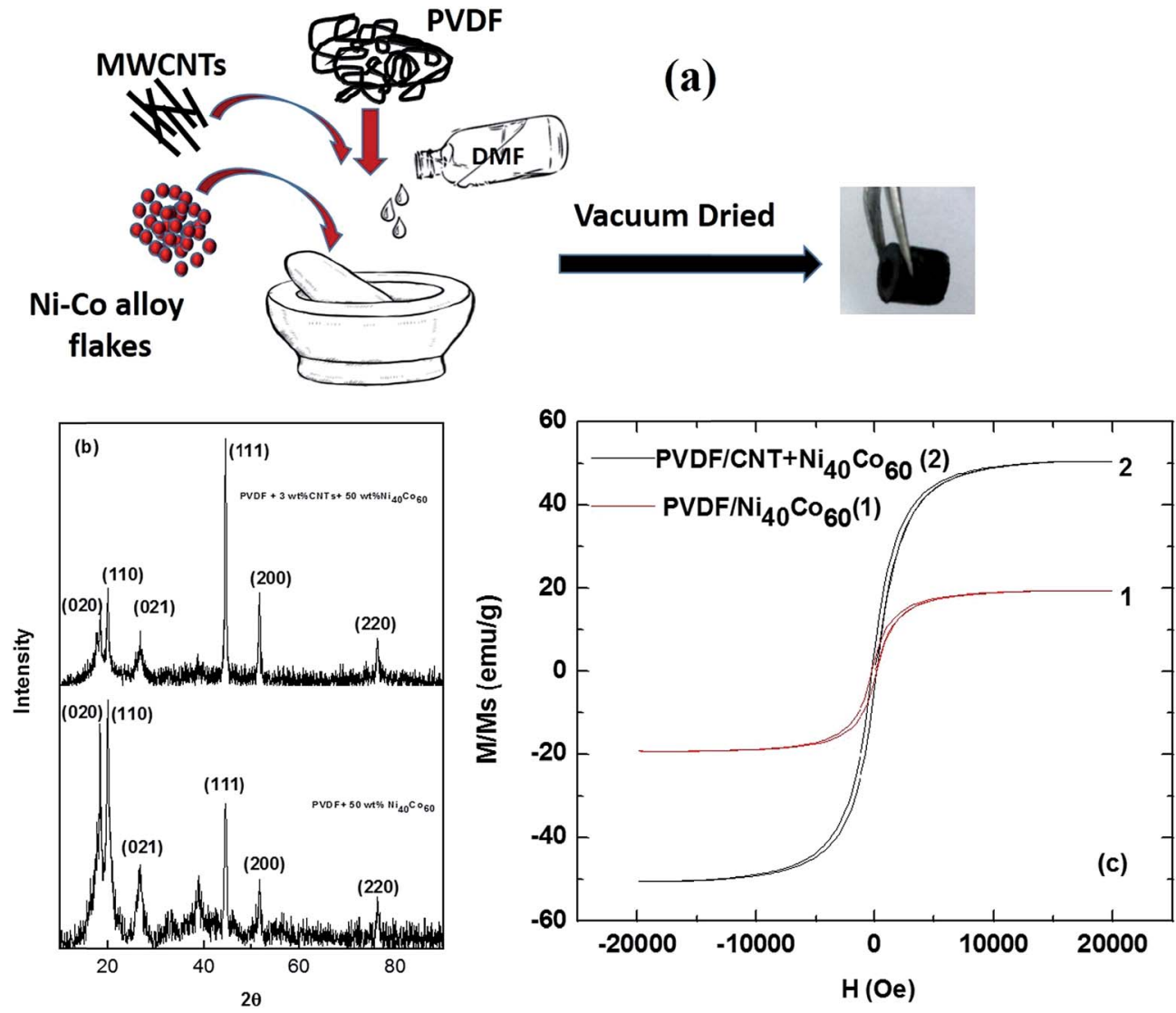

Fig. 2 (a) Preparation of PVDF/CNT/Ni-Co composite (b) XRD pattern for PVDF/CNTs-Ni-Co composite (c) hysteresis loop for PVDF/Ni ${ }_{40} \mathrm{CO}_{60}$ and PVDF/CNT/Ni ${ }_{40} \mathrm{Co}_{60}$ composite.

3.3 Synergistic improvement in electrical conductivity: effect of Ni-Co alloy and CNT

Fig. 4 shows the AC electrical conductivity of the composites as a function of frequency. The electrical conductivity of insulating PVDF has increased to $1.7 \times 10^{-5} \mathrm{~S} \mathrm{~cm}^{-1}$ with the addition of $3 \mathrm{wt} \%$ CNTs as observed from Fig. 4. The addition of $\mathrm{Ni}_{40} \mathrm{Co}_{60}$ flakes $(20 \mathrm{wt} \%)$ has shown slight increase in conductivity $(6.5 \times$ $\left.10^{-5} \mathrm{~S} \mathrm{~cm}^{-1}\right)$. Interestingly, the electrical conductivity significantly enhanced to $1.7 \times 10^{-4} \mathrm{~S} \mathrm{~cm}^{-1}$ on addition of $3 \mathrm{wt} \%$ CNTs and $50 \mathrm{wt} \% \mathrm{Ni}_{40} \mathrm{Co}_{60}$ flakes in PVDF. Such an impressive improvement in the electrical conductivity suggests synergistic improvement from both Ni-Co and CNTs. In order to understand the mechanism of charge transport in PVDF based composites, the AC electrical conductivity data was fitted using a power law lat-29 $^{27}$ expessed as,

$$
\sigma_{\mathrm{AC}}(\omega)=\sigma_{\mathrm{DC}}(\omega)+A(\omega)^{s}
$$

where, $\sigma_{\mathrm{DC}}$ is the DC conductivity at $\omega \rightarrow 0, \omega$ is the angular frequency and $A$ and $s$, are frequency and temperature dependent parameters. The value of $s$, determined from the fits of $\ln (\sigma)$ with $\ln (\omega)$, indicates the conduction mechanism in the sample. The value of $s$ is ca. 0.65 for $\mathrm{PVDF} / \mathrm{CNT} / \mathrm{Ni}_{40} \mathrm{Co}_{60}$ composites suggesting tunnelling of electrons.

\subsection{Attenuating electromagnetic waves: effect of $\mathrm{Ni}-\mathrm{Co}$ alloy and CNT}

Shielding by absorption $\left(\mathrm{SE}_{\mathrm{A}}\right)$, reflection $\left(\mathrm{SE}_{\mathrm{R}}\right)$ and total shielding effectiveness $\left(\mathrm{SE}_{\mathrm{T}}\right)$ are evaluated from the scattering parameters $\left(S_{11}\right.$ and $\left.S_{12}\right)$ using the following equations,

$$
\begin{gathered}
\mathrm{SE}_{\mathrm{A}}=10 \log _{10}\left(\left(1-\left[S_{11}\right]^{2}\right) /\left[S_{12}\right]^{2}\right) \\
\mathrm{SE}_{\mathrm{R}}=10 \log _{10}\left(1 /\left(1-\left[S_{11}\right]^{2}\right)\right) \\
\mathrm{SE}_{\mathrm{T}}=\mathrm{SE}_{\mathrm{A}}+\mathrm{SE}_{\mathrm{R}}=10 \log _{10}\left(1 /\left[S_{12}\right]^{2}\right)
\end{gathered}
$$

Fig. 5a shows the shielding effectiveness of PVDF/NiCo composite with different composition of NiCo alloy. It is evident that shielding effectiveness scales with increasing concentration of Co in the composites. It has already been reported that the control PVDF is transparent to EM radiation. ${ }^{8}$ The maximum SE with $60 \mathrm{wt} \%$ cobalt is $c a .27 \mathrm{~dB}$. On the other hand, after addition of 20 and $40 \mathrm{wt} \%$ cobalt, the SE achieved are 17 and $23 \mathrm{~dB}$ respectively while only $13 \mathrm{~dB}$ of SE is achieved without addition of cobalt. The increase in shielding effectiveness is due to relatively higher magnetic permeability of Co as compared to Ni. From the calculated values of reflection and absorption parameters, it is evident that absorption dominates over reflection. At $3 \mathrm{wt} \%$ CNTs in 

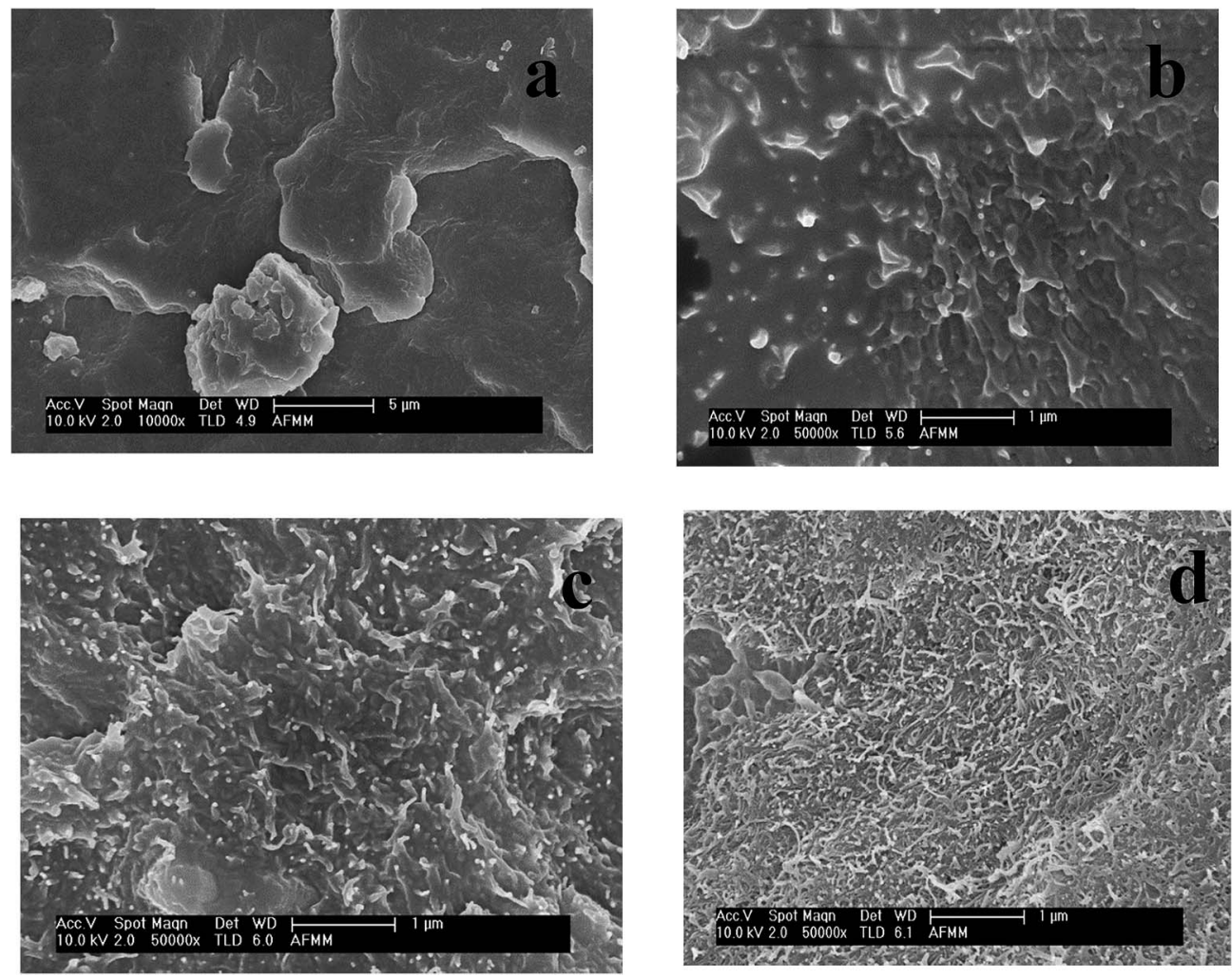

Fig. 3 SEM images of PVDF/CNT/Ni ${ }_{40} \mathrm{Co}_{60}$ composites: (a) neat PVDF (b) PVDF/Ni ${ }_{40} \mathrm{Co}_{60}$ (c) PVDF/CNTs (d) PVDF/CNT/Ni ${ }_{40} \mathrm{Co}{ }_{60}$.

PVDF matrix, SE value of the composite reached $22 \mathrm{~dB}$ while with the addition of $50 \mathrm{wt} \%$ of $\mathrm{Ni}_{40} \mathrm{Co}_{60}$ flakes, a drastic increase in the SE $c a$. $41 \mathrm{~dB}$ has been observed as shown in Fig. 5b. This sudden jump in the $\mathrm{SE}$ value is due to the synergistic effect of the conducting CNTs and high permeability of $\mathrm{Ni}_{40} \mathrm{Co}_{60}$ flakes.

EM absorbing characteristics were evaluated by relative complex permittivity and permeability. The real and imaginary

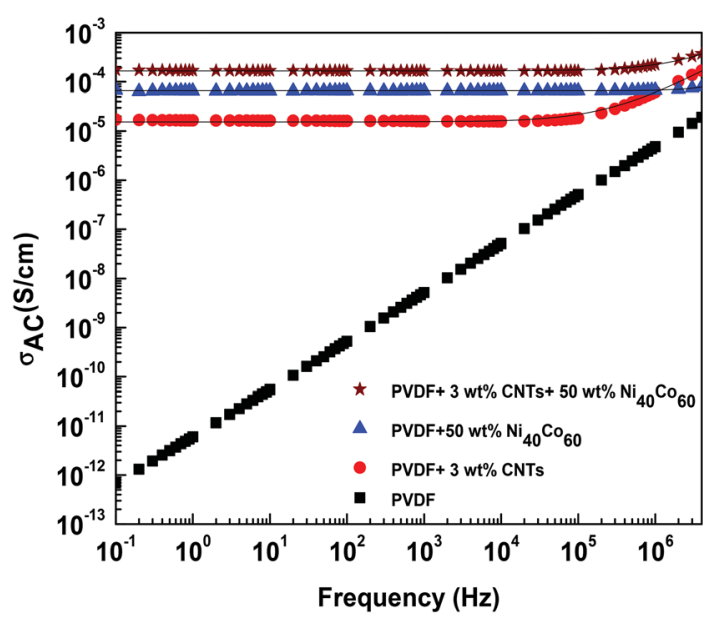

Fig. 4 Dependence of electrical conductivity on frequency for PVDF composite with different concentration of $\mathrm{Ni}_{40} \mathrm{Co}_{60}$ alloy and CNTs. Black solid line indicates the fitted data. parts represent the storage and loss of EM wave energy, respectively. The relative complex permittivity and permeability were calculated from the scattering parameters $\left(S_{11}\right.$ and $\left.S_{12}\right)$ obtained from the VNA in the range of $2-18 \mathrm{GHz}$ by the Nicolson-Ross model. ${ }^{30}$ The sum and difference of scattering parameters can be expressed as follows:

$$
\begin{aligned}
& V_{1}=S_{21}-S_{11} \\
& V_{2}=S_{21}+S_{11}
\end{aligned}
$$

The reflection coefficient on the interface with air-filled coaxial line can be expressed using the following equation:

$$
\Gamma=\frac{Z-Z_{0}}{Z+Z_{0}}=\frac{\left(\sqrt{\mu_{\mathrm{R}} / \varepsilon_{\mathrm{R}}}-1\right)}{\left(\sqrt{\mu_{\mathrm{R}} / \varepsilon_{\mathrm{R}}}+1\right)}
$$

Similarly, the transmission coefficient of the specimen with particular thickness $t$ can be expressed as below:

$$
z=e^{-j \omega \sqrt{\mu \varepsilon t}}=e^{(-j(\omega / c)) \sqrt{\mu_{\mathrm{R}} \varepsilon_{\mathrm{R}} t}}
$$

where, $\varepsilon_{\mathrm{R}}$ and $\mu_{\mathrm{R}}$ are complex permittivity and permeability respectively. $Z_{0}$ is characteristic impedance and $Z$ is new characteristic impedance of specimen.

Therefore, reflection coefficient may be calculated from scattering parameters as shown below.

$$
\Gamma=X \pm \sqrt{X^{2}-1}
$$



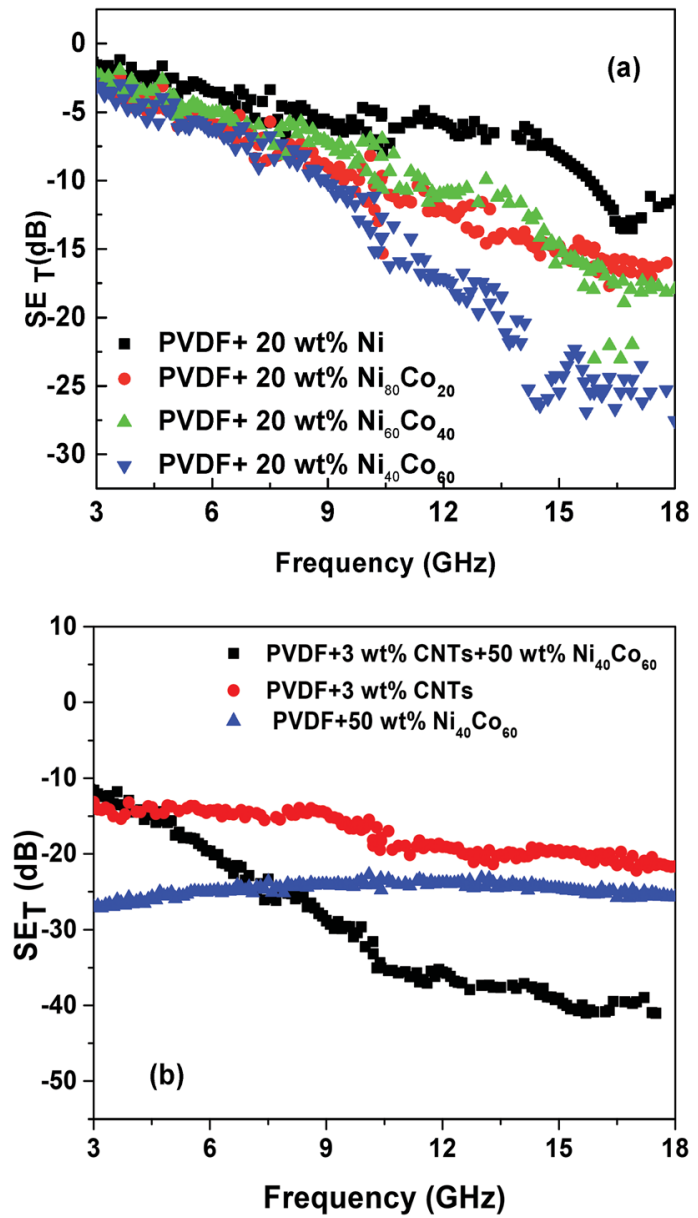

Fig. 5 Shielding effectiveness (a) PVDF composites with different concentration of $\mathrm{Ni}-\mathrm{Co}$ alloy (b) PVDF composites with different concentration $\mathrm{Ni}-\mathrm{Co}$ alloy and CNTs.

where,

$$
X=\frac{1-V_{1} V_{2}}{V_{1}-V_{2}}
$$

For $|\Gamma| \leq 1$ appropriate sign can be chosen.

From (8) and (9) we can define,

$$
\begin{gathered}
\frac{\mu_{\mathrm{R}}}{\varepsilon_{\mathrm{R}}}=\left[\frac{1+\Gamma}{1-\Gamma}\right]^{2}=c_{1} \\
\mu_{\mathrm{R}} \varepsilon_{\mathrm{R}}=-\left[\frac{c}{\omega t} \ln \left(\frac{1}{z}\right)\right]^{2}=c_{2}
\end{gathered}
$$

Thus, the relative permeability and permittivity is expressed as,

$$
\begin{gathered}
\mu_{\mathrm{R}}=\sqrt{c_{1} c_{2}} \\
\varepsilon_{\mathrm{R}}=\sqrt{\frac{c_{1}}{c_{2}}}
\end{gathered}
$$

The frequency dependent relative permittivity and relative permeability of $\mathrm{PVDF} / \mathrm{CNTs}-\mathrm{Ni}_{40} \mathrm{Co}_{60}$ composite are shown in Fig. $6 \mathrm{a}$ and $\mathrm{b}$, respectively. The relative permittivity profile shows two broad peaks in the frequency range of 8-11 and 15-17 GHz, as observed from Fig. 6a. The peaks correspond to relaxation loss associated with interfacial polarization occurring due to electronegativity difference between $\mathrm{Ni}$-Co alloy and CNTs. ${ }^{14,24}$ It is important to note that the peaks at 6 and $15 \mathrm{GHz}$ also suggest the resonance behaviour in the system. This is possible only when the composite sample is highly conducting exhibiting skin effect. ${ }^{31,32}$

Similarly, three peaks were observed in the relative complex permeability profile as shown in Fig. $6 \mathrm{~b}$. These peaks correspond to resonance peaks at a certain frequency and refers to high magnetic loss. ${ }^{33}$ These magnetic losses could be due to eddy current effect, hysteresis loss, flux shunting, ${ }^{34}$ natural resonance and exchange resonance. ${ }^{14}$ The dominant shielding mechanism and subsequently the SE depend on the geometry of the shield (and source), frequency of the source and the material parameters.$^{35} \mathrm{~A}$ conducting shell with low permeability can also be effective shielding material due to eddy currents. ${ }^{34}$ Therefore, higher SE can be obtained either by increasing the material permeability or the material thickness. ${ }^{35}$ In the present context, eddy current loss is the dominant shielding mechanism..$^{14,34}$

The EM wave consists of electric and magnetic field, which oscillates perpendicular to each other and to the direction of energy propagation. It is envisaged that when a conductor is subjected to an external electric field, within a very short time, the mobile charge inside the medium will rearrange themselves in such a way that they neutralize the effect of the original electric field. Inside an isolated conductor at equilibrium, no electrostatic field can exist. Therefore, inside a conductor, the macroscopic charge density is zero, so a net charge can exist only at the surface in a conducting material. Hence, the inner region is shielded from the effects of the external electrostatic field.

In addition, at low frequencies, the magnetic field is either due to the electric current flowing inside the conductors or due to the magnetization of surrounding ferromagnetic materials. The shield in fact causes a change in the behavior of the field, diverting the lines of the magnetic induction away from the shielded region.

Fig. $6 c$ shows the dependence of reflection loss calculated using the following equations,

$$
\begin{gathered}
Z_{\text {in }}=Z_{0}\left(\mu_{\mathrm{R}} / \varepsilon_{\mathrm{R}}\right)^{1 / 2} \tanh \left[j(2 \pi f t / c)\left(\mu_{\mathrm{R}} \varepsilon_{\mathrm{R}}\right)^{1 / 2}\right] \\
\mathrm{RL}=20 \log \left|\left(Z_{\text {in }}-Z_{0}\right) /\left(Z_{\text {in }}+Z_{0}\right)\right|
\end{gathered}
$$

where, $t$ is the thickness of the absorber, $f$ is the frequency of the EM wave, $c$ is the velocity of the light, $Z_{0}$ is the impedance of vacuum and $Z_{\text {in }}$ is the input impedance of the absorber. ${ }^{14,30}$

The shield thickness is another key factor; if penetration is the dominant mechanism, a thicker shield results in improved shielding. An EM field can be diverted by means of an alternative path, not necessarily enclosing the area to be shielded. Such 

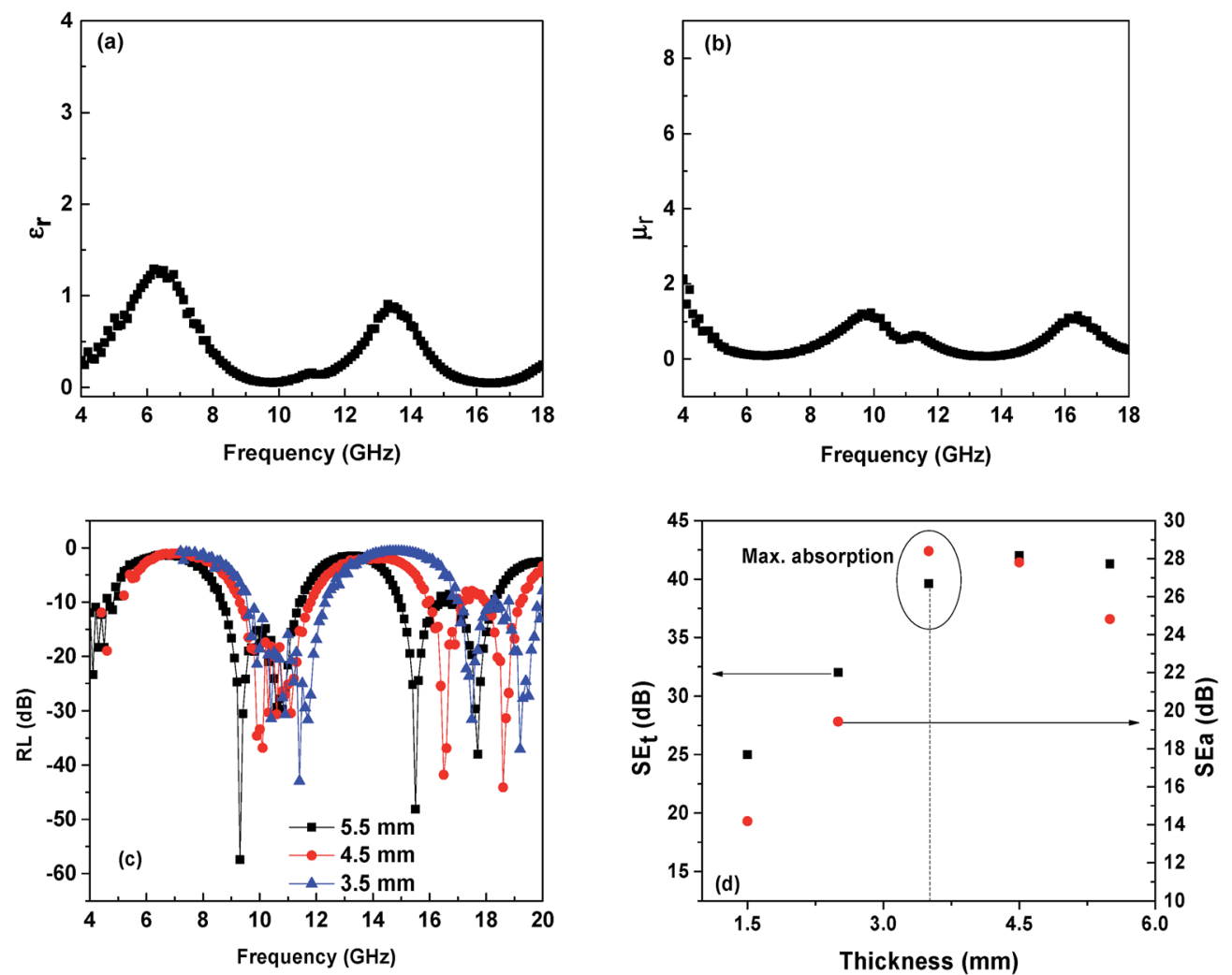

Fig. 6 (a) Relative complex permittivity and (b) permeability (c) dependence of RL on frequency at different thicknesses for PVDF + 3 wt\% CNTs + 50 wt $\% \mathrm{Ni}_{40} \mathrm{CO}_{60}$ composite (d) absorption and total SE with different thickness for PVDF +3 wt\% CNTs +50 wt\% Ni ${ }_{40} \mathrm{CO}_{60}$ composite.

a path may offer better propagation characteristics to the electric field (by means of highly conducting materials), the electric induction (by means of high permittivity materials), the magnetic induction (high permeability materials). From Fig. 6d, it is evident that the reflection loss (RL) values depend on the thickness of the samples. As the thickness increases, the RL shifts to lower frequency. ${ }^{14}$ It is clear that PVDF/CNT/Ni $\mathrm{Ni}_{40} \mathrm{Co}_{60}$ composite exhibits strong absorption in the measured range of frequency. The $\mathrm{RL}$ for $\mathrm{PVDF} / \mathrm{CNT} / \mathrm{Ni}_{40} \mathrm{Co}_{60}$ composite sample with $5.5 \mathrm{~mm}$ thickness is $c a$. $56.5 \mathrm{~dB}$ at $4.29 \mathrm{GHz}$. In addition, a

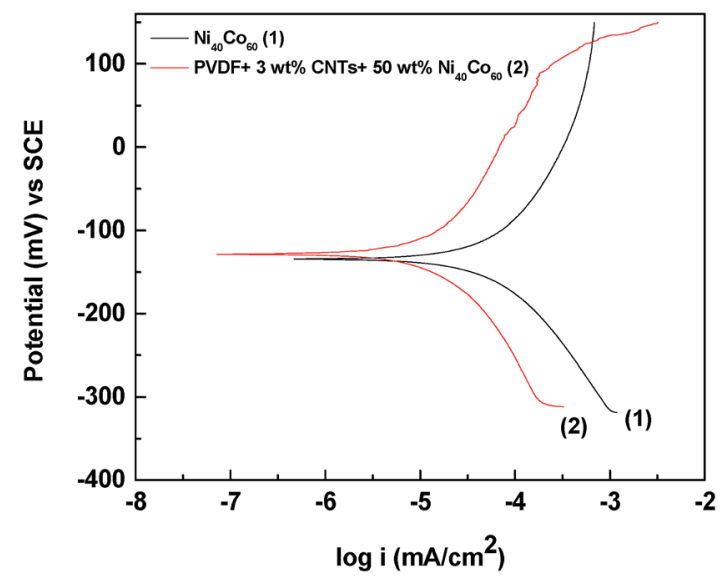

Fig. 7 Potentio-dynamic polarization plots in $0.5 \% \mathrm{NaCl}$ solution. minimum RL of $c a \cdot 43.1 \mathrm{~dB}$ at $11.4 \mathrm{GHz}$ for the sample of $3.5 \mathrm{~mm}$ thickness and a RL of $c a .44 .1 \mathrm{~dB}$ at $18.6 \mathrm{GHz}$ for the sample of $4.5 \mathrm{~mm}$ thicknesses was observed. It is envisaged that high frequency can penetrate only a thin surface of electrically conducting material known as skin depth $(\delta)$, defined as the depth at which the field drops to $1 / e$ of the incident value and is represented as follows,

$$
\delta=\left(\frac{2}{f \mu \sigma}\right)^{1 / 2}=-8.68\left(\frac{t}{\mathrm{SE}_{\mathrm{A}}}\right)
$$

where, $f$ is the frequency, $\sigma$ is the electrical conductivity, $\mu$ is the magnetic permeability and $t$ is the thickness of the material. A skin depth of $1.09 \mathrm{~mm}$ was achieved for $5.5 \mathrm{~mm}$ thick sample and it can be concluded that $\mathrm{PVDF} / \mathrm{CNT} / \mathrm{Ni}_{40} \mathrm{Co}_{60}$ composite can absorb microwave radiation. The absorption and total shielding effectiveness for PVDF/CNT/ $\mathrm{Ni}_{40} \mathrm{Co}_{60}$ composite with different thickness is shown in Fig. 6d. Maximum absorption was obtained for the sample with $3.5 \mathrm{~mm}$ thickness (71\%).

\subsection{Corrosion resistant composites}

The corrosion resistance of $\mathrm{PVDF} / \mathrm{CNTs}-\mathrm{Ni}_{40} \mathrm{Co}_{60}$ composite and $\mathrm{Ni}_{40} \mathrm{Co}_{60}$ alloy was carried out by using Potentio-dynamic polarization in $0.5 \% \mathrm{NaCl}$ solution. The corrosion potential $\left(E_{\text {corr }}\right)$ and corrosion current density $\left(I_{\text {corr }}\right)$ were evaluate from Tafel extrapolation method. From Fig. 7, it is evident that the corrosion rate has decreased from $7.76 \times 10^{-5}$ to $2.34 \times 10^{-5}$ $\mathrm{mA} \mathrm{cm}{ }^{-2}$ after incorporation of $\mathrm{Ni}_{40} \mathrm{Co}_{60}$ alloy in PVDF/CNT 
composites. Thus, these composites can be further be explored as lightweight, corrosion resistant materials for attenuating EM radiation.

\section{Conclusions}

Lightweight, flexible, and corrosion resistant PVDF based composites was prepared using a unique process. The Ni-Co alloy was prepared by vacuum arc melting process and mixed with CNTs. The XRD pattern for Ni-Co alloy shows FCC crystal structure. The VSM study confirms that the PVDF/CNT/Ni $\mathrm{Ni}_{40} \mathrm{Co}_{60}$ composite show almost similar saturation magnetization as that of neat Nickel. In addition, 50 wt $\%$ of $\mathrm{Ni}_{40} \mathrm{Co}_{60}$ in PVDF/CNT composites showed significant improvement in electrical conductivity as compared to PVDF/CNTs and $\mathrm{PVDF} / \mathrm{Ni}_{40} \mathrm{Co}_{60}$ composites. Intriguingly, $\mathrm{PVDF} / \mathrm{CNT} / \mathrm{Ni}_{40} \mathrm{Co}_{60}$ composite showed an impressive enhancement in $\mathrm{SE}$ and absorbed $c a .70 \%$ of the total incident EM radiation.

\section{Acknowledgements}

The authors like to acknowledge Department of Science and Technology DST, India for financial support. Authors also like to acknowledge Prof. Subodh Kumar for extending corrosion facilities.

\section{References}

1 A. Ahlbom, J. Bridges, R. De Seze, L. Hillert, J. Juutilainen, M.-O. Mattsson, G. Neubauer, J. Schüz, M. Simko and K. Bromen, Toxicology, 2008, 246, 248-250.

2 K. Jagatheesan, A. Ramasamy, A. Das and A. Basu, Indian J. Fibre Text. Res., 2014, 39, 329-342.

3 J. Arranz-Andrés, E. Pérez and M. Cerrada, Eur. Polym. J., 2012, 48, 1160-1168.

4 J. Arranz-Andrés, N. Pulido-González, C. Fonseca, E. Perez and M. Cerrada, Mater. Chem. Phys., 2013, 142, 469-478.

5 V. Udmale, D. Mishr, R. Gadhave, D. Pinjare and R. Yamgar, Orient. J. Chem., 2013, 29, 927-936.

6 S. Aalto, C. Haarala, A. Brück, H. Sipilä, H. Hämäläinen and J. O. Rinne, J. Cereb. Blood Flow Metab., 2006, 26, 885-890.

7 S. P. Pawar, K. Pattabhi and S. Bose, Assessing the critical concentration of $\mathrm{NH}_{2}$ terminal groups on the surface of MWNTs towards chain scission of PC in PC/SAN blends: effect on dispersion, electrical conductivity and EMI shielding, RSC Adv., 2014, 4(36), 18842-18852.

8 M. Sharma, M. P. Singh, C. Srivastava, G. Madras and S. Bose, ACS Appl. Mater. Interfaces, 2014, 6, 21151-21160.

9 M. Oyharçabal, T. Olinga, M.-P. Foulc, S. Lacomme, E. Gontier and V. Vigneras, Compos. Sci. Technol., 2013, 74, 107-112.

10 A. P. Singh, B. K. Gupta, M. Mishra, G. A. Chandra, R. B. Mathur and S. K. Dhawan, Carbon, 2013, 56, 86-96.

11 M. Sharma, S. Sharma, J. Abraham, S. Thomas, G. Madras and S. Bose, Mater. Res. Express, 2014, 1, 035003.
12 J. Wei, T. Wang and F. Li, J. Magn. Magn. Mater., 2011, 323, 2608-2612.

13 S. J. Yan, C. Y. Xu, J. T. Jiang, D. B. Liu, Z. Y. Wang, J. Tang and L. Zhen, J. Magn. Magn. Mater., 2014, 349, 159-164.

14 C. Feng, X. Liu, Y. Sun, C. Jin and Y. Lv, RSC Adv., 2014, 4, 22710-22715.

15 X. Liu, S. W. Or, Y. Sun, W. Li, Y. He, G. Zhu, C. Jin, Q. Yan, Y. Lv, S. L. Ho and S. Zhao, J. Alloys Compd., 2013, 548, 239244.

16 M.-S. Cao, J. Yang, W.-L. Song, D.-Q. Zhang, B. Wen, H.-B. Jin, Z.-L. Hou and J. Yuan, ACS Appl. Mater. Interfaces, 2012, 4, 6949-6956.

17 X. Liu, S. W. Or, C. Jin, Y. Lv, C. Feng and Y. Sun, Carbon, 2013, 60, 215-220.

18 Z. Zhu, X. Sun, G. Li, H. Xue, H. Guo, X. Fan, X. Pan and J. He, J. Magn. Magn. Mater., 2015, 377, 95-103.

19 X. Shui and D. D. L. Chung, J. Electron. Mater., 1997, 26, 928934.

20 X. Shui and D. D. L. Chung, J. Mater. Sci., 2000, 35, 17731785.

21 C. Gong, Y. Duan, J. Tian, Z. Wu and Z. Zhang, J. Appl. Polym. Sci., 2008, 110, 569-577.

22 R. Han, L. Qiao, T. Wang and F.-s. Li, J. Alloys Compd., 2011, 509, 2734-2737.

23 L. F.-S. XUE De-Sheng, F. A. N. Xiao-Long and W. E. N. FuSheng, Chin. Phys. Lett., 2008, 25, 4120-4123.

24 H. Wang, H. Guo, Y. Dai, D. Geng, Z. Han, D. Li, T. Yang, S. Ma, W. Liu and Z. Zhang, Appl. Phys. Lett., 2012, 101, 083116.

25 R. Madhavan, R. K. Ray and S. Suwas, Acta Mater., 2014, 78, 222-235.

26 R. Madhavan, R. K. Ray and S. Suwas, Acta Mater., 2014, 74, 151-164.

27 G. C. Psarras, Composites, Part A, 2006, 37, 1545-1553.

28 G. Psarras, E. Manolakaki and G. Tsangaris, Composites, Part A, 2002, 33, 375-384.

29 G. C. Psarras, E. Manolakaki and G. M. Tsangaris, Composites, Part A, 2003, 34, 1187-1198.

30 X. Liu, C. Feng, S. W. Or, C. Jin, F. Xiao, A. Xia, W. Li, Y. Sun and S. Zhao, Mater. Res. Bull., 2013, 48, 3887-3891.

31 R. Zhuo, L. Qiao, H. Feng, J. Chen, D. Yan, Z. Wu and P. Yan, J. Appl. Phys., 2008, 104, 094101.

32 H. Li, Y. Huang, G. Sun, X. Yan, Y. Yang, J. Wang and Y. Zhang, J. Phys. Chem. C, 2010, 114, 10088-10091.

33 H. Pan, X. Cheng, C. Zhang, C. Gong, L. Yu, J. Zhang and Z. Zhang, Appl. Phys. Lett., 2013, 102, 012410.

34 S. Celozzi, R. Araneo and G. Lovat, in Electromagnetic Shielding, John Wiley \& Sons, Inc., 2008, pp. 282-316, DOI: 10.1002/9780470268483.app2.

35 X. C. Tong, in Advanced Materials and Design for Electromagnetic Interference Shielding, CRC Press, 2008, ch. 1, DOI: 10.1201/9781420073591. 